\title{
Um olhar sobre o modelo analítico de Clive Ashwin aplicado nas ilustrações de Vera Cruz artista gráfico em Pernambuco - fins do século XIX e início do século $X X$
}

An examination of Clive Ashwin's analytical model applied in the illustrations of Vera Cruz a graphic artist in Pernambuco - from the end of the $19^{\text {th }}$ and beginning of the $20^{\text {th }}$ century

Íkaro Santhiago Câmara Silva Oliveira; Solange Galvão Coutinho

memória gráfica, modelo analítico, Clive Ashwin, artista gráfico, Vera Cruz

Este artigo revisita o modelo analítico que trata dos ingredientes de estilo de ilustrações desenvolvido por Clive Ashwin em 1979, aplicando-o em um conjunto de dez ilustrações de Antonio Vera Cruz, um artista gráfico (ilustrador e litógrafo) que fez história em Pernambuco no final do século XIX. Almeja-se através deste estudo verificar as características que compõem o estilo gráfico deste artista no espaço amostral selecionado. Inicialmente as etapas do processo metodológico são descritas e posteriormente utilizadas no decorrer do artigo auxiliando na apresentação da pesquisa desenvolvida. Na sequência é apresentado o objeto de estudo e sua relação com o design da informação e a memória gráfica, chegando por fim a apresentação do modelo analítico e sua aplicação nos grupos de ilustrações selecionados. Todas as ilustrações apresentadas neste trabalho foram coletadas pelos autores deste artigo a partir de fotografias, com base nas pesquisas realizadas no acervo da Biblioteca Pública do Estado de Pernambuco.

\section{graphic memory, analytical model, Clive Ashwin, graphic artist, Vera Cruz}

This article reexamines the analytical model that deals with the ingredients of style in illustrations developed by Clive Ashwin in 1979, applying it to a set of ten illustrations by Antonio Vera Cruz, a graphic artist (lithographer and illustrator) who made history in Pernambuco in the late nineteenth century. Thus, the study aims to verify characteristics that compose the graphic style of this artist in the selected temporal sample. Initially the steps of the methodological process are described and later used throughout the article to assist presenting the research developed. Sequentially, we present the object of study and its relation with information design and graphic memory, concluding with a presentation of the analytical model and its application in the groups of selected illustrations. All illustrations presented in this work were collected by the authors of this article from photographs, based on research carried out on the collection at the Public Library of the State of Pernambuco.

\section{Introdução}

A partir do levantamento do estado da arte acerca das metodologias que ligavam o design da informação a artefatos de memória gráfica, motivados pela pesquisa em andamento acerca do artista gráfico Antonio Vera Cruz (ilustrador, litógrafo e um dos pioneiros das artes gráficas em Pernambuco no final do século XIX), realizamos uma revisão de artigos publicados entre 2010 e 2015 nos anais dos congressos (CIDI e $P \& D)$. Os mesmos foram escolhidos atendendo os seguintes critérios: apresentar relação com a temática do design da informação; a memória gráfica; ao estudo de variáveis gráficas e a utilização de modelos analíticos em artefatos gráficos. Nesse pequeno espaço amostral doze artigos foram selecionados (seguem nas referências) atendendo a pelo menos dois destes critérios citados. A maioria (onze artigos) apresenta ligação estreita entre o design da informação e algum artefato de memória gráfica: Impressos efêmeros da indústria gráfica recifense do século XX; Rótulos de cachaça; Letreiramentos populares da paisagem urbana do Recife; Catálogos de tipos móveis do século XIX; Capas de disco de vinil; Catálogos da Pinacoteca de São Paulo; Anúncios publicitários de revista da década de 1950 e 1990.

Durante a análise do processo metodológico dos artigos pode-se evidenciar algumas etapas em comum entre eles, e como o objeto de estudo do presente artigo possui relação com

Anais do $8^{\circ} \mathrm{CIDI}$ e $8^{\circ} \mathrm{CONGIC}$

Guilherme Santa Rosa; Cristina Portugal (orgs.)

Sociedade Brasileira de Design da Informação - SBDI

Natal | Brasil | 2017

ISBN
Proceedings of the $8^{\text {th }} \mathrm{CIDI}$ and $8^{\text {th }}$ CONGIC

Guilherme Santa Rosa; Cristina Portugal (orgs.)

Sociedade Brasileira de Design da Informação - SBDI

Natal| Brazil | 2017

ISBN 
a memória gráfica, foi possível relacionar algumas destas etapas com os estudos que vem sendo desenvolvidos e também utilizá-las como metodologia neste artigo.

\section{Etapas do processo metodológico}

As etapas metodológicas comuns encontradas nos artigos relacionadas ao processo de pesquisa em design da informação para artefatos de memória gráfica foram:

- Revisão bibliográfica;

- Relacionar o objeto de estudo com o design da informação e a memória gráfica;

- Apresentação do contexto histórico;

- Análise do problema (contexto da pesquisa);

- Pesquisa de campo exploratória; Coleta e apresentação de dados encontrados nos arquivos;

- Recorte do universo de pesquisa (buscando construir agrupamentos);

- Fichamento, numeração e catalogação das amostras dos artefatos coletados;

- Desenvolvimento e apresentação do instrumento de análise (fichas, tabelas, etc.);

- Aplicação de instrumento de análise (descrição do artefato, análise do conteúdo, da organização informacional e das características do estilo gráfico);

- Discussão dos resultados.

No tocante aos modelos analíticos citados nos artigos foram encontrados: Michel Twyman (1979); Clive Ashwin (1979); Evelyn Goldsmith (1984); Martine Joly (1996); Carla Galvão Spinillo (2000); Sue Walker (2001). Dentre esses modelos o desenvolvido por Clive Ashwin, que será descrito em detalhes, foi escolhido para nortear o processo analítico deste estudo, por ser aquele que mais se adequou aos objetivos do mesmo que visa encontrar características, que de acordo com este autor, podem apontar o estilo gráfico em um conjunto de ilustrações, neste caso aquelas selecionadas a partir da obra de Antonio Vera Cruz.

\section{As ilustrações de Vera Cruz, o design da informação e a memória gráfica}

Em meados do século XIX em Pernambuco a cultura dos impressos se disseminava e ganhava espaço dentro do cotidiano da sociedade do período. Aos poucos os avanços tecnológicos para a reprodução de imagens, principalmente a partir da técnica da litografia, começaram a ser cada vez mais utilizados para estampar diversas publicações do período, surgiram assim, as chamadas Revistas llustradas.

A partir da década de 1860 cresce a quantidade de periódicos dedicados à sátira política e à crônica de costumes. Eles constituem a face mais conhecida da memória gráfica brasileira do século XIX. Em sua maioria, as edições são formadas por uma única folha com duas dobras alternadas, gerando um caderno de oito páginas [...] a ilustração domina as capas, sendo os títulos das publicações invariavelmente tratados como desenhos, numa fusão entre texto e imagem. (Melo \& Ramos, 2011: 47)

Muitos artistas gráficos tiveram destaque neste período, Cavalcanti (2005: 60) cita, Antonio Vera Cruz (figura 1), como "um artista que desfrutava de uma técnica e um estilo superiores, sendo um dos melhores do Brasil em sua época [...] a postura liberal de Vera Cruz permitiu retratar os principais acontecimentos da história nacional".

Figura 1: Fotografia de Antonio Vera Cruz.

Fonte: Feições Artísticas (1907), de Bianor de Medeiros, acervo da Biblioteca Pública do Estado de Pernambuco.

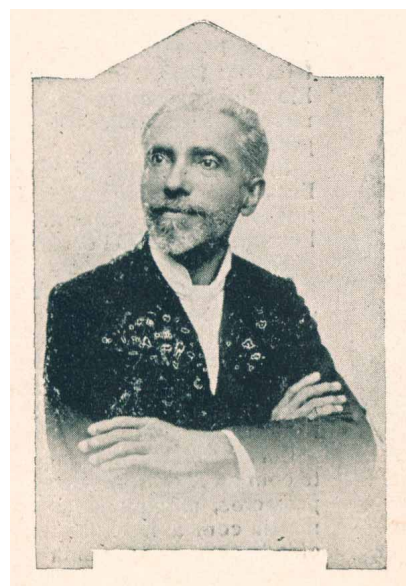

Anais do $8^{\circ}$ Congresso Internacional de Design da Informação | CIDI 2017

Proceedings of the $8^{\text {th }}$ Information Design International Conference। CIDI 2017 
Querino (1911: 87-88) revela dados importantes sobre as origens deste ilustrador, nascido em 1858, na cidade baiana de Cachoeira, transferiu-se para o Recife em 1873 e aqui permaneceu em atividade até 1902. Começou sua carreira em Salvador estudando desenho com Bento José Rufino Capinam e na revista Bahia llustrada iniciou seus trabalhos litográficos.

Sobre a litografia que significa "desenhar na pedra", técnica desenvolvida em 1796 por Aloys Senefelder (1771-1834), Meggs descreve:

A litografia se baseia no princípio químico simples que óleo e água não se misturam. A imagem é desenhada numa superfície plana de pedra com crayon, caneta ou lápis de base oleosa, que repele a água. Em seguida, uma tinta também de base oleosa é passada com um rolo sobre a pedra, aderindo a imagem, mas não as áreas molhadas. Uma folha de papel é colocada sobre a imagem e utiliza-se uma prensa para transferir a imagem entintada para o papel. (Meggs, 2009: 198)

Vera Cruz mostrou-se um exímio mestre nesta técnica e foi no Recife que consolidou sua carreira de ilustrador, chargista, caricaturista através de desenhos satíricos e críticos da politica e dos costumes da época em diversos periódicos, assinando geralmente suas obras com um V. seguido ao sinal da cruz. De acordo com Nascimento $(1970,1972)$ e Magno (2012: 341) suas ilustrações aparecem intercalando-se por vezes em periódicos como O Diabo a Quatro (1876-1879), América llustrada (1877-1879), Os Xênios (1878-1879), O Etna (1881-1882), A Exposição (1887-1888), Recife llustrado (1888) e diversas Polianteias ${ }^{1}$. Além do jornalismo ilustrado também surge em Cunha Lima, relacionando-o com a litografia comercial como ilustrador de rótulos de cigarro:

A grande maioria dos litógrafos desenhistas é anônima. Mas foi possível identificar ao menos alguns deles que assinaram seus desenhos. Os mais importantes são Frese e Antonio Vera Cruz [...] é tipicamente um homem de jornal. Numa época em que estas profissões ainda não haviam se separado com clareza, ele era retratista e caricaturista, fazendo conhecidas as faces das personalidades e distorcendo-as para criticar a sociedade. Estas duas facetas de seu desenho estão presentes nos rótulos que desenha. (Cunha Lima, 2000: 11)

O levantamento realizado até o momento mostrou que Vera Cruz também foi responsável pela a criação de quadros e aquarelas que datam do início do século XX. Para este estudo foram selecionadas ilustrações do periódico que Cavalcanti (1996: XII) ressaltou: "A mais importante revista ilustrada deste final do século XIX, porém, vem a ser O Diabo a Quatro Revista infernal, trazendo ilustrações e charges de José Neves e Antônio Vera Cruz".

O Diabo a Quatro - Revista Infernal, foi o periódico no qual Vera Cruz fez sua estreia na imprensa pernambucana, circulou semanalmente no Recife entre 11 de julho de 1875 a 15 de maio de 1879, possuía cunho humorístico e crítico, seus desenhos ocupando a capa, as páginas centrais e a contracapa, aliados a parte textual, apoiavam a política liberal republicana, satirizavam o Governo Imperial, e ainda faziam crônicas de costumes e hábitos do período.

Uma das definições de Jacobson para o design da informação pode ser relacionada ao trabalho executado por Vera Cruz em O Diabo a Quatro:

Minha crença é que há uma prática de design exclusivo que pode ser identificado como o design de informação. Sua finalidade é a disposição sistemática e utilização de veículos de comunicação, canais e símbolos para aumentar a compreensão dos participantes em uma conversa ou discurso específico.

(Jacobson, 2000: 8-9)

De certa forma foi exatamente isso que este artista fez, em um momento onde a sociedade passava por intensas transformações provenientes da crise do governo imperial e sua ligação com a Igreja Católica representantes de uma sociedade conservadora, que se confrontava com as ideias liberais republicanas, da abolição da escravidão e do advento da modernidade do século XX que estava por vir. Adepto das ideias liberais, Vera Cruz conseguiu transmitir e organizar toda esta gama de informações através de surpreendentes ilustrações litografadas repletas de linguagens visuais e simbólicas, que aliadas a doses satíricas de bom humor se tornaram propagadoras de informações e discursos, que enquanto divertiam também estimulavam o senso crítico da sociedade da época, deixando raízes para o trabalho das futuras gerações de artistas gráficos.

\footnotetext{
${ }^{1}$ Eram impressos que tinham o objetivo de homenagear uma personalidade ilustre, de notoriedade social (artistas, políticos, estadistas), ou comemorar algum célebre acontecimento. Tinham quase um caráter de "edições especiais", pois diferente das revistas ilustradas que geralmente circulavam durante um longo período, a maioria das polianteias tiveram apenas um número, as exceções ocorriam quando homenageavam por exemplo temporadas artísticas ou companhias teatrais.
} 
As ilustrações de Vera Cruz se constituem como artefatos históricos e de memória gráfica, ao resgata-las além da preservação estamos contando a história do design, pois elas carregam consigo informações sobre a cultura, o contexto e a sociedade na qual foram produzidas, assim como expressam a forma de pensar e fazer design em uma determinada época.

\section{Modelo analítico de Clive Ashwin}

Em "The ingredients of style in contemporary illustration: A case study", publicado em 1979, Clive Ashwin, reflete sobre o conceito de "estilo", ao tratar de imagens gráficas. Para o autor, o estilo de uma ilustração deve ir mais além, refletindo sobre as peculiaridades da própria imagem. Ele desenvolveu - o que podemos categorizar como - um modelo analítico, baseado nas funções sintáticas e semânticas das ilustrações. Ao propor este modelo Ashwin definiu alguns ingredientes que podem ser encontrados em qualquer ilustração independente do período em que foi criada.

No total são sete os ingredientes ou variáveis, que segundo ele estão presentes em qualquer ilustração, cada ingrediente possui dois polos nos quais as características da ilustração podem ser enquadradas durante uma análise. Segundo Ashwin se a variável ficar neutra entre os dois polos a mesma perde um pouco da força, perante alguma outra variável que tenha o polo concentrado no extremo.

A interação intrínseca e a repetição entre as sete variáveis e seus polos auxiliam na definição de características que apontam o estilo da ilustração de um artista, época ou cultura. $\mathrm{Na}$ (figura 2) estão demonstradas as variáveis (destacadas com cores que irão identificá-las nas tabelas de análise das ilustrações posteriormente apresentadas) e seus polos. $\mathrm{Na}$ sequência cada variável e seus respectivos polos serão definidos e exemplificados com ilustrações de O Diabo a Quatro de autoria de Vera Cruz, extraídas dos exemplares da revista, por meio de fotografias realizadas no acervo da Biblioteca Pública do Estado de Pernambuco. Deve-se salientar que mesmo os exemplos sendo utilizados para destacar apenas um dos polos, que possui maior evidência na ilustração selecionada, é possível encontrar elementos de todas as variáveis em uma mesma ilustração.

Figura 2: Variáveis e polos do modelo analítico de Clive Ashwin. Fonte: Elaborada pelos autores, com base na pesquisa realizada.

\begin{tabular}{r|rl|}
\hline \multicolumn{1}{|c|}{ VARIÁVEIS } & \multicolumn{2}{|c|}{ POLOS } \\
\hline Consistência. & Homogênea & Heterogênea \\
\hline Gama & Contraído & Expandido \\
\hline Enquadramento & Disjuntivo & Conjuntivo \\
\hline Posicionamento & Simétrico & Casual \\
\hline Proximidade & Perto & Distante \\
\hline Cinética & Estático & Dinâmico \\
\hline Naturalismo & Naturalista & Não Naturalista \\
\hline
\end{tabular}

CONSISTÊNCIA - Conforme Ashwin (1979: 58) diz respeito as técnicas de representação e as ferramentas utilizadas na elaboração ou produção da ilustração. Os polos desta variável são: Homogêneo, quando não apresenta variações das técnicas de produção, por exemplo, um desenho de linha constante; Heterogêneo, quando apresenta uma variedade de técnicas de produção, como a mistura de texto e imagem pictórica (desenho, fotografia etc.). Nas figuras 3 e 4 apesar de ambas as ilustrações terem como principal técnica de elaboração a litografia, a (figura 4) apresenta texto com caligrafia cursiva mesclado e complementando as cenas, ao desenhar letras Vera Cruz utilizou outro traço ou técnica aproximando-a ao polo heterogêneo, enquanto a (figura 3) mais simples e apenas com imagens pictóricas se enquadra no polo homogêneo. 
Figuras 3 e 4: Respectivamente exemplos dos polos Homogêneo e Heterogêneo. Fonte: O Diabo a Quatro, acervo da $\left(\mathrm{BPE}^{2}\right)$.
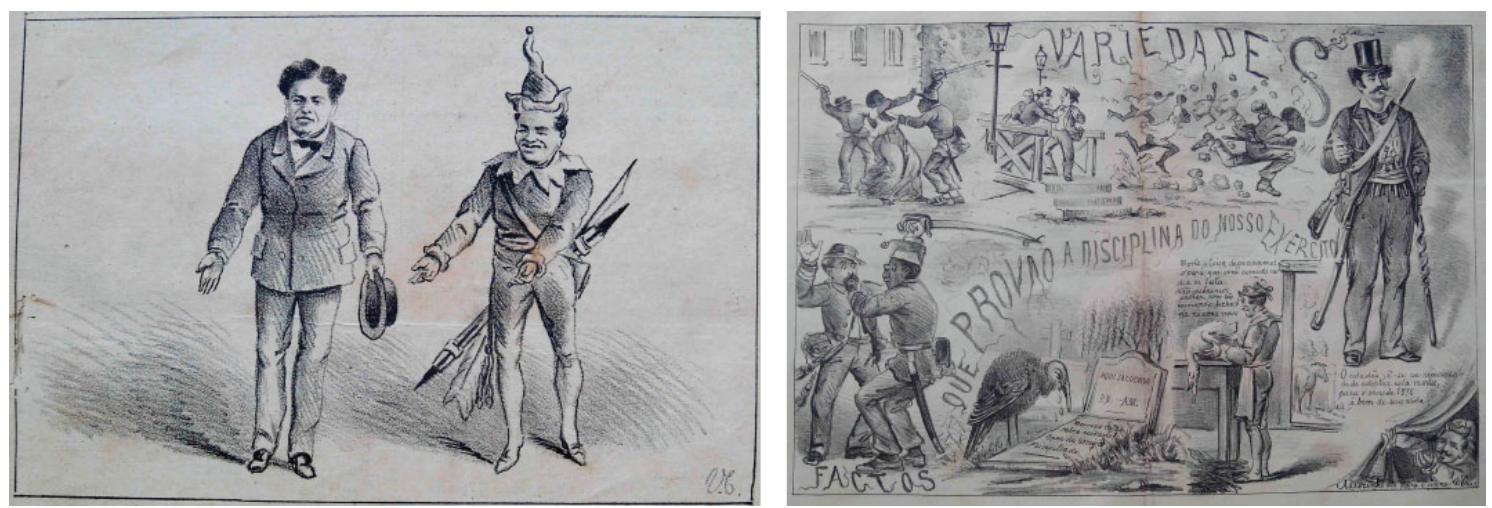

GAMA - Segundo Ashwin (1979: 59), pode ser evidenciada através da escolha entre utilizar todas as possibilidades sintáticas na imagem ou se concentrar em seguir apenas um caminho. Se relaciona ao nível de detalhes dos elementos que compõem a ilustração. Seus polos são: Contraído e Expandido, comparando as ilustrações abaixo é possível evidenciar que a (figura 6) apresenta maior riqueza de detalhes nos móveis, dobras de tecidos e a noção de profundidade por conta do trabalho de sombra realizado pelo desenhista, a gama é expandida e apresenta uma quantidade de traços maior na sua elaboração se comparada a gama contraída da (figura 5).

Figuras 5 e 6: Respectivamente exemplos dos polos Contraído e Expandido. Fonte: O Diabo a Quatro, acervo da (BPE).
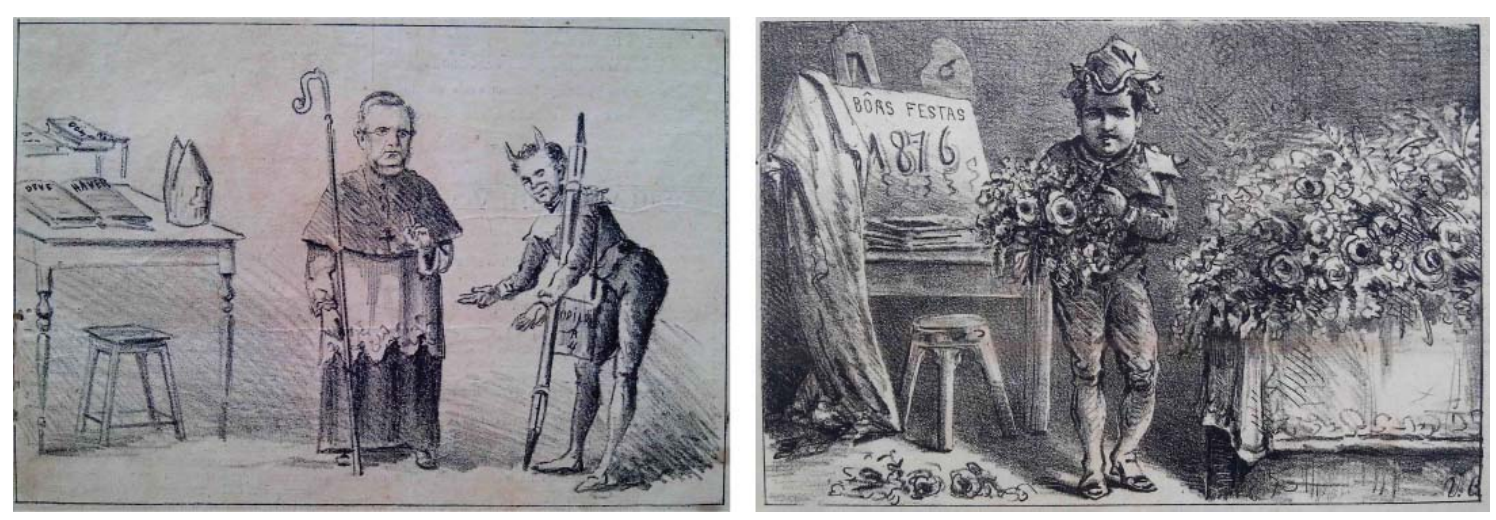

ENQUADRAMENTO - Ashwin (1979: 60), destaca que esta variável encontra-se relacionada à disposição da imagem pictórica em seu suporte. Fica fácil evidenciar esta relação ao observarmos a (figura 7) onde os dois personagens estão totalmente inseridos no quadro não existe cenário ou qualquer elemento vazado, outro detalhe da imagem é a figura sob o fundo branco, a atenção acaba se voltando a figura, este polo é denominado Disjuntivo. Entretanto analisando a cena da (figura 8) diversos personagens que acompanham o padre falar no púlpito estão incompletos e de outros só se vê sombras, o próprio ambiente onde se encontram os personagens também vai além dos limites do quadro, cabe ao observador da ilustração imaginar o restante da cena, em casos em que os elementos ultrapassam os limites do suporte, e também enfatizam a interação entre a figura e o ambiente (cenário), explorando a ideia de conjunto nos aproximamos do polo Conjuntivo. O modo conjuntivo na ilustração é, portanto, empregado para criar um senso de profusão e diversidade, enquanto o modo disjuntivo pode ser utilizado para focar a atenção do espectador.

${ }^{2}$ BPE - Biblioteca Pública do Estado de Pernambuco. 
Figuras 7 e 8: Respectivamente exemplos dos polos Disjuntivo e Conjuntivo. Fonte: O Diabo a Quatro, acervo da (BPE).
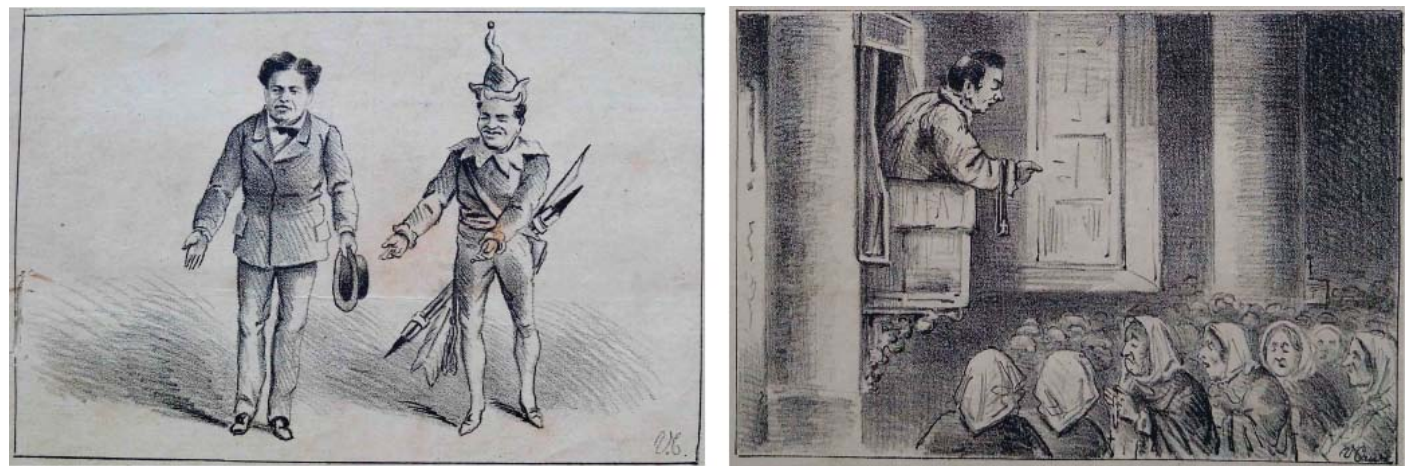

POSICIONAMENTO - Para Ashwin (1979: 62) é caracterizado pelo arranjo dos componentes da ilustração, sugerindo uma ideia de ordem ou causalidade. Na historieta em quadrinhos (figura 9) os personagens e ações estão alinhados de maneira a sugerir uma ordem, uma simetria entre os elementos que a compõem caracterizando o polo Simétrico. A (figura 10) além de não apresentar um alinhamento visual perfeito sugerindo uma aleatoriedade entre os componentes da imagem, ainda apresenta variações de proporção e tamanho dos personagens que a compõem aproximando a ilustração do polo Casual.

Figuras 9 e 10: Respectivamente exemplos dos polos Simétrico e Casual. Fonte: O Diabo a Quatro, acervo da (BPE).
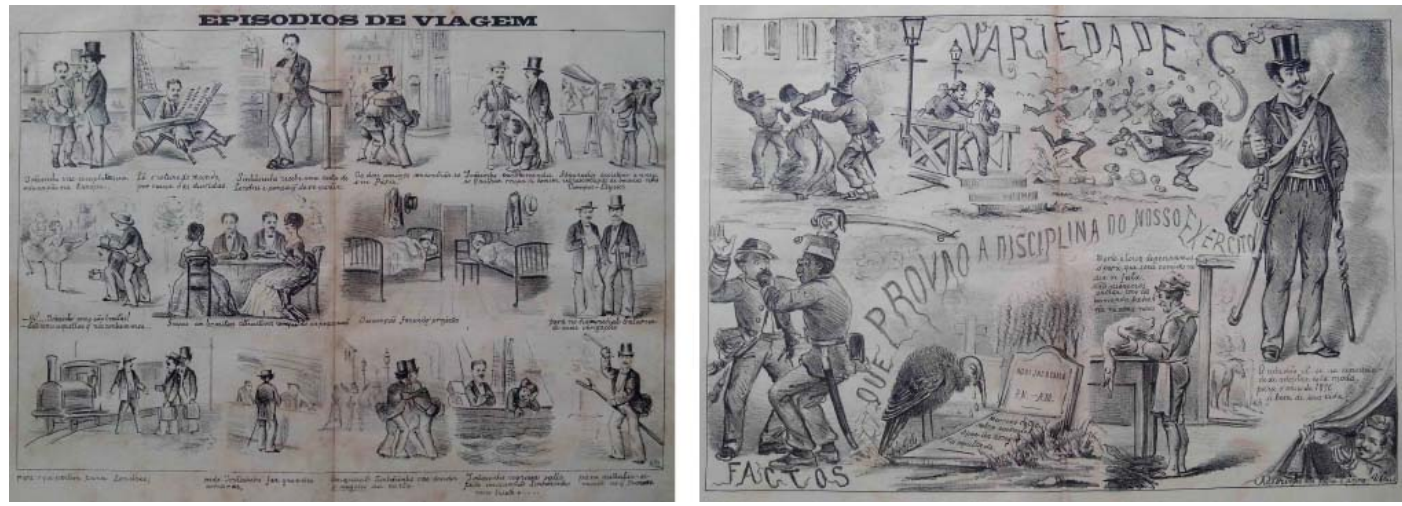

PROXIMIDADE - Ashwin (1979: 63), descreve como a distância implícita entre o observador e o objeto, neste caso a imagem ilustrativa. A sensação de perto ou distante resulta da relação de escala entre os elementos pictóricos principais da imagem e a área da ilustração. Os bustos apresentados na (figura 11), polo Perto encontram-se próximos aos olhos do observador, essa sensação fica ainda mais evidente se a compararmos com a (figura 12) uma historieta em quadrinhos na qual o personagem principal encontrasse pequenino repetido em 20 quadros em que é desenhado realizando ações variadas, representando o polo Distante.

Figuras 11 e 12: Respectivamente exemplos dos polos Perto e Distante. Fonte: O Diabo a Quatro, acervo da (BPE).
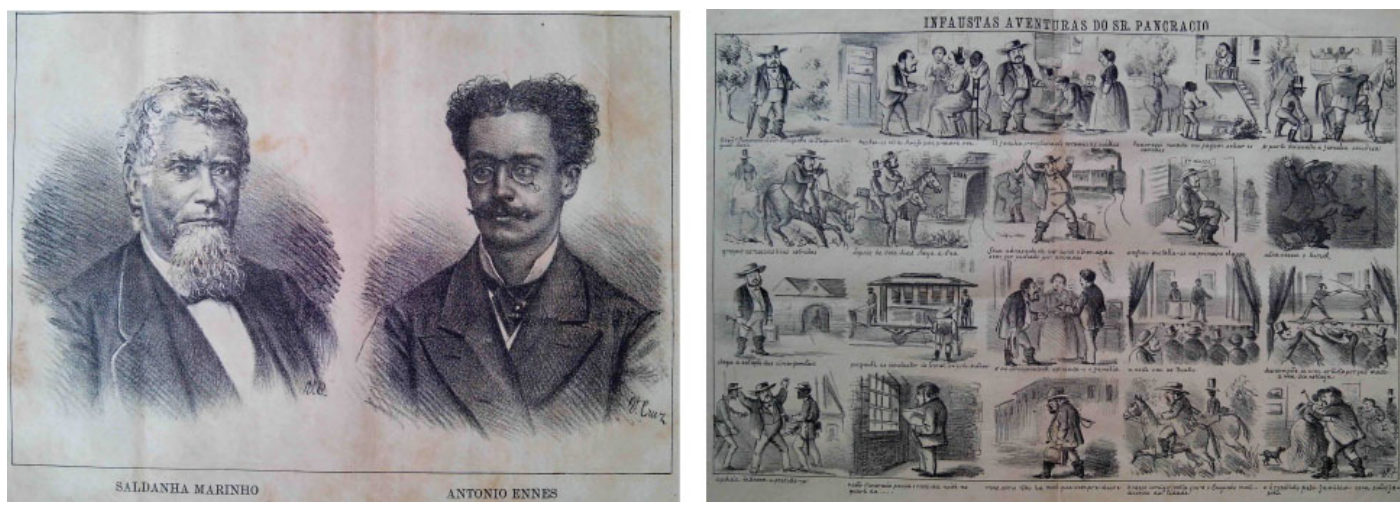

Anais do $8^{\circ}$ Congresso Internacional de Design da Informação | CIDI 2017

Proceedings of the $8^{\text {th }}$ Information Design International Conference | CIDI 2017 
CINÉTICA - É a variável que segundo Ashwin (1979: 64) analisa a representação gráfica dentro de um contexto de tempo-espaço. Auxilia na compreensão de movimento em uma ilustração. Mesmo a ilustração sendo estática, é possível sugerir movimento por meio de representações gráficas como linhas de velocidade (speed lines), recurso muito utilizado em histórias em quadrinhos. A (figura 13) enquadrada no polo Estático apresenta uma noção de movimento na inclinação do diabrete perante o padre, mas é um movimento quase estático se comparado a (figura 14) onde existem inúmeros personagens correndo e no canto esquerdo dois homens que parecem brigar conferem uma atmosfera de movimento a praticamente todos os personagens aproximando a ilustração do polo Dinâmico.

Figuras 13 e 14: Respectivamente exemplos dos polos Estático e Dinâmico. Fonte: O Diabo a Quatro, acervo da (BPE).
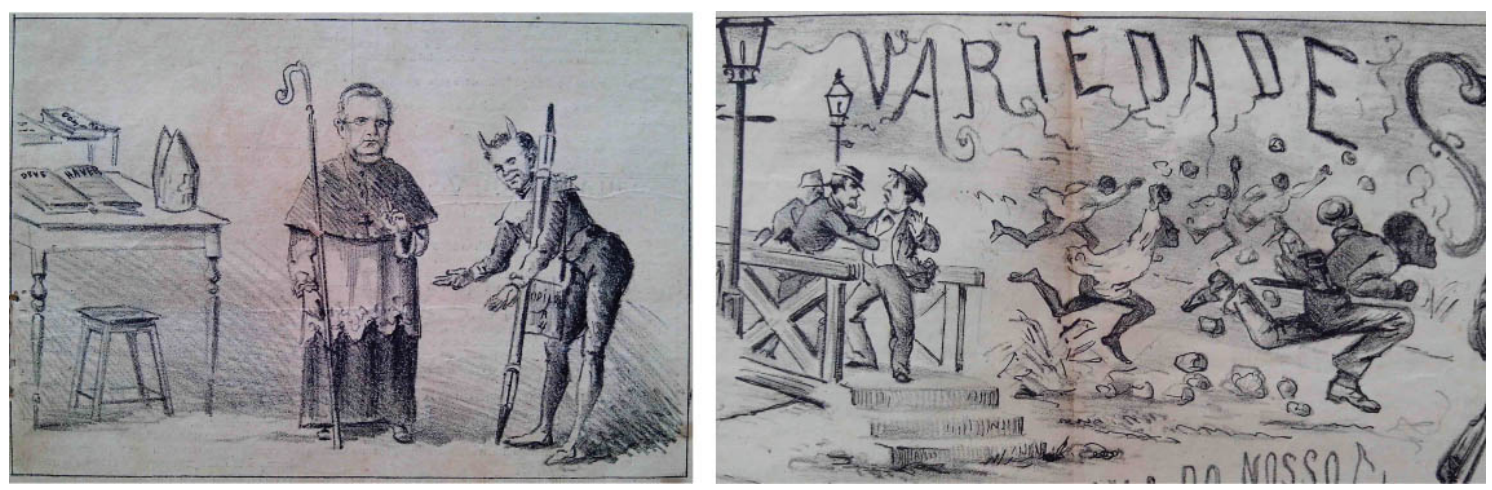

NATURALISMO - Conforme Ashwin (1979: 66), situa os elementos pictóricos dentro de uma concepção da relação física com o mundo em que vivemos e a nossa noção de realidade. O grau de naturalismo de uma ilustração é calculado pela plausibilidade do que está sendo mostrado, demonstra se os elementos da ilustração podem ocorrer no mundo real. A cena representada na (figura 15) é classificada como polo Naturalista, pois mostra padres e mulheres religiosas se encontrando na rua, uma ação totalmente possível de ocorrer no mundo real e muito comum no período onde havia uma forte influência da igreja Católica, porém a cena retratada na (figura 16) com uma figura feminina e crianças flutuando sobre um globo é caracterizada por elementos que fogem da realidade do mundo físico, representando o polo Não Naturalista.

Figuras 15 e 16: Respectivamente exemplos dos polos Naturalista e Não Naturalista. Fonte: O Diabo a Quatro, acervo da (BPE).
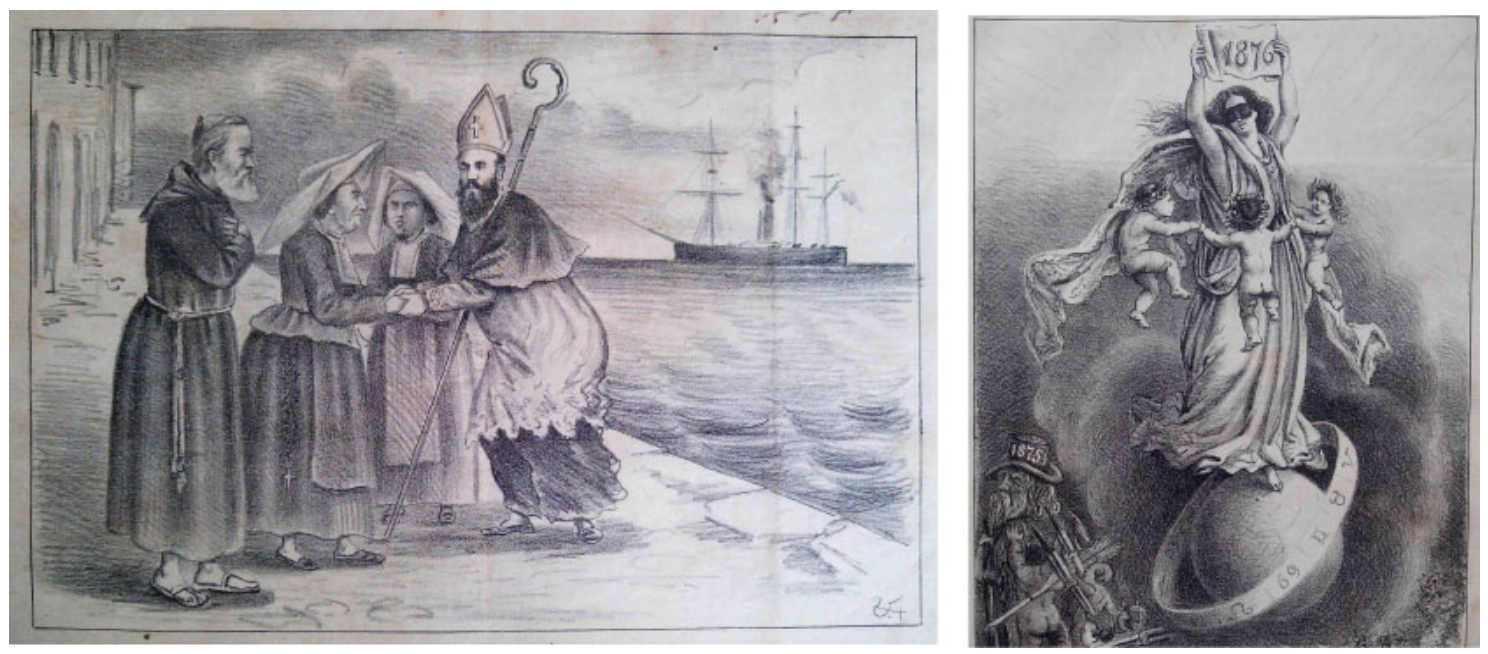

Anais do $8^{\circ}$ Congresso Internacional de Design da Informação | CIDI 2017

Proceedings of the $8^{\text {th }}$ Information Design International Conference | CIDI 2017 


\section{Delimitação do Espaço Amostral e Aplicação do Modelo Analítico}

Durante a fase de estudo das definições das variáveis do modelo analítico de Ashwin, foi possível evidenciar a partir dos exemplos citados anteriormente, que o mesmo poderia ser aplicado nas ilustrações de Vera Cruz. Para este experimento objetivando verificar se a aplicação do modelo em um conjunto de ilustrações deste artista revelaria traços de seu estilo gráfico, foram selecionadas dez ilustrações de O Diabo a Quatro divididas em dois grupos de cinco ilustrações cada.

GRUPO 1 | llustração Central - Teve como critério de seleção ilustrações que ocupavam as páginas centrais da revista e que tivessem temáticas ligadas a relação entre o Estado Monárquico e a Igreja Católica, que era um alvo constante de críticas por parte dos ilustradores ligados a imprensa nacional. Essa relação era enfatizada pelo artigo $5^{\circ}$ da Constituição monárquica que estabelecia o regime do padroado, um privilégio herdado da coroa portuguesa. Fornecia ao Imperador o direito do beneplácito sobre as encíclicas papais, ou seja, para que uma ordem do Vaticano vigorasse no Brasil dependia da aprovação do monarca (Hoornaert, 1983). E os membros do clero eram assim vistos como funcionários públicos. Este poder do imperador gerou o que ficaria conhecida como a "questão religiosa" entre os anos de 1872 a 1878 , quando D. Pedro II então simpatizante da maçonaria se negou a aceitar uma ordem do Papa Pio IX, que determinava a expulsão dos maçons das irmandades religiosas, chegando inclusive a prender por cerca de dois anos os bispos de Olinda, D. Vital Maria e do Pará, D. Antônio de Macedo que obedeceram as ordens papais sobrepondo o poder temporal da Igreja sobre o poder civil do Governo Imperial. Esses personagens e acontecimentos aparecem nas ilustrações selecionadas no Grupo 1.

GRUPO 2 | llustração de Capa - Teve como critério de seleção aquelas que ocupavam as capas, dos exemplares que formam o Grupo 1, apresentam temáticas variadas (citações a artistas, políticos e aos próprios desenhistas e redatores da revista retratados como diabretes).

A figura 17 apresenta os exemplares nos quais foram extraídas as ilustrações dos Grupos. A ordem alfabética de $A$ a $E$, também tem a função de identificar as ilustrações durante a fase de análise dos resultados, principalmente nas figuras 21 e 22 - tabelas 2 de resumo de resultados que serão apresentadas posteriormente.

Figura 17: Exemplares de O Diabo a Quatro que formam os grupos de ilustrações selecionados. Fonte: Elaborada pelos autores, com base na pesquisa realizada.

$$
\begin{aligned}
& \text { A O Diabo a Quatro, } n^{\circ} 12-26.09 .1875 \\
& \text { B O Diabo a Quatro, } n^{\circ} 15-17.10 .1875 \\
& \text { C O Diabo a Quatro, } n^{\circ} 19-14.11 .1875 \\
& \text { D O Diabo a Quatro, } n^{\circ} 20-21.11 .1875 \\
& \text { E O Diabo a Quatro, } n^{\circ} 46-21.05 .1876
\end{aligned}
$$

Após a delimitação dos Grupos de ilustrações a serem estudados foi desenvolvida uma ficha de análise, exemplificada na (figura 18) apresentando a ilustração que foi analisada, seguida das informações do grupo e dados de origem da mesma, e uma tabela contendo os sete variáveis do modelo analítico de Ashwin e seus respectivos polos em escala numérica e de cor que variam do nível 1 ao $4^{3}$. Cada variável foi analisada e demarcada com sua respectiva cor na tabela, variando entre os níveis da escala à medida que as características encontradas nas ilustrações observadas se aproximavam mais das características que Ashwin determinou para cada polo. Deve se ressaltar que esta foi uma análise subjetiva de cada ilustração, visto que as marcações ocorreram de acordo com as opiniões e o entendimento dos

\footnotetext{
${ }^{3}$ Os níveis apresentados neste artigo, não fazem parte da descrição de Ashwin (1979), mas foi adicionada a esta análise pelos autores, por compreender que uma gradação dos polos, poderia descrever com mais acuidade o grau de adesão a cada um deles: (4) se total, (3) quase total, (2) parcial ou (1) pouco homogêneo e heterogêneo, por exemplo. Adotando-se assim este sistema de gradação para todos os polos das sete variáveis.
} 
autores deste artigo a respeito do modelo analítico de Ashwin. Concluída a fase de marcação dos polos foi traçada uma linha percorrendo o trajeto entre as variáveis seus polos.

Figura 18: Ficha de Analise - aplicação do modelo analítico.

Fonte: Elaborada pelos autores, com base na pesquisa realizada.

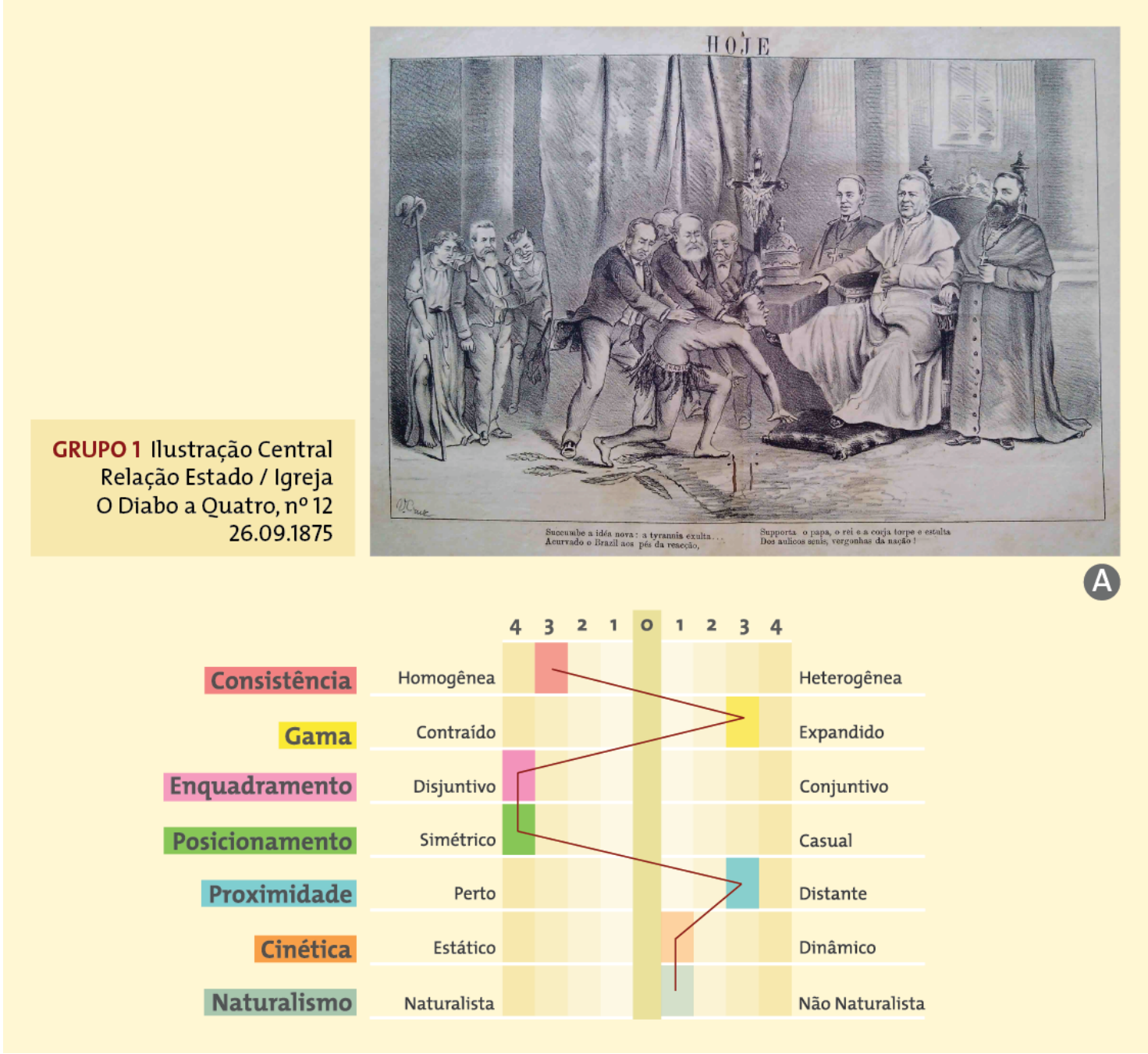

\section{Resultados}

A partir da análise individual de cada ilustração que compõem os Grupos 1 e 2 foram originadas dois tipos de tabelas de resumo de resultados para cada grupo. Nas primeiras tabelas (figuras 19 e 20) foram realizadas a sobreposição de todas as marcações dos polos e o cruzamento das linhas de trajeto traçadas entre as variáveis e seus polos. Foi possível evidenciar que em alguns casos um mesmo nível de um polo foi marcado mais de uma vez, assim para que ficasse claro este pormenor, em cada quadro marcado foi colocado o número de vezes que o mesmo foi escolhido e se repetiu durante a fase de análise. 
Figura 19: Tabela 1 de resumo de resultados do Grupo 1.

Fonte: Elaborada pelos autores, com base na pesquisa realizada.

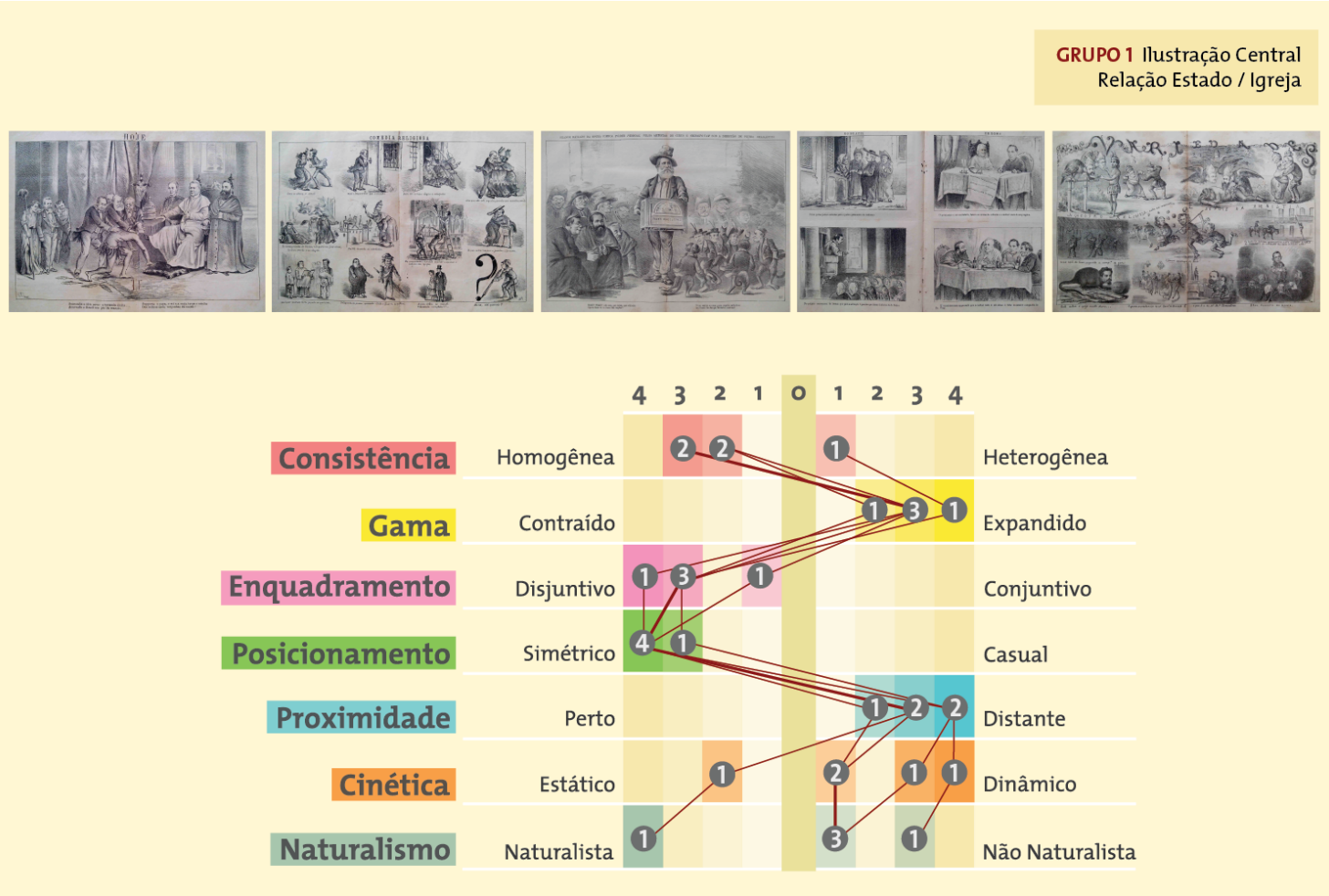

Figura 20: Tabela 1 de resumo de resultados do Grupo 2.

Fonte: Elaborada pelos autores, com base na pesquisa realizada.

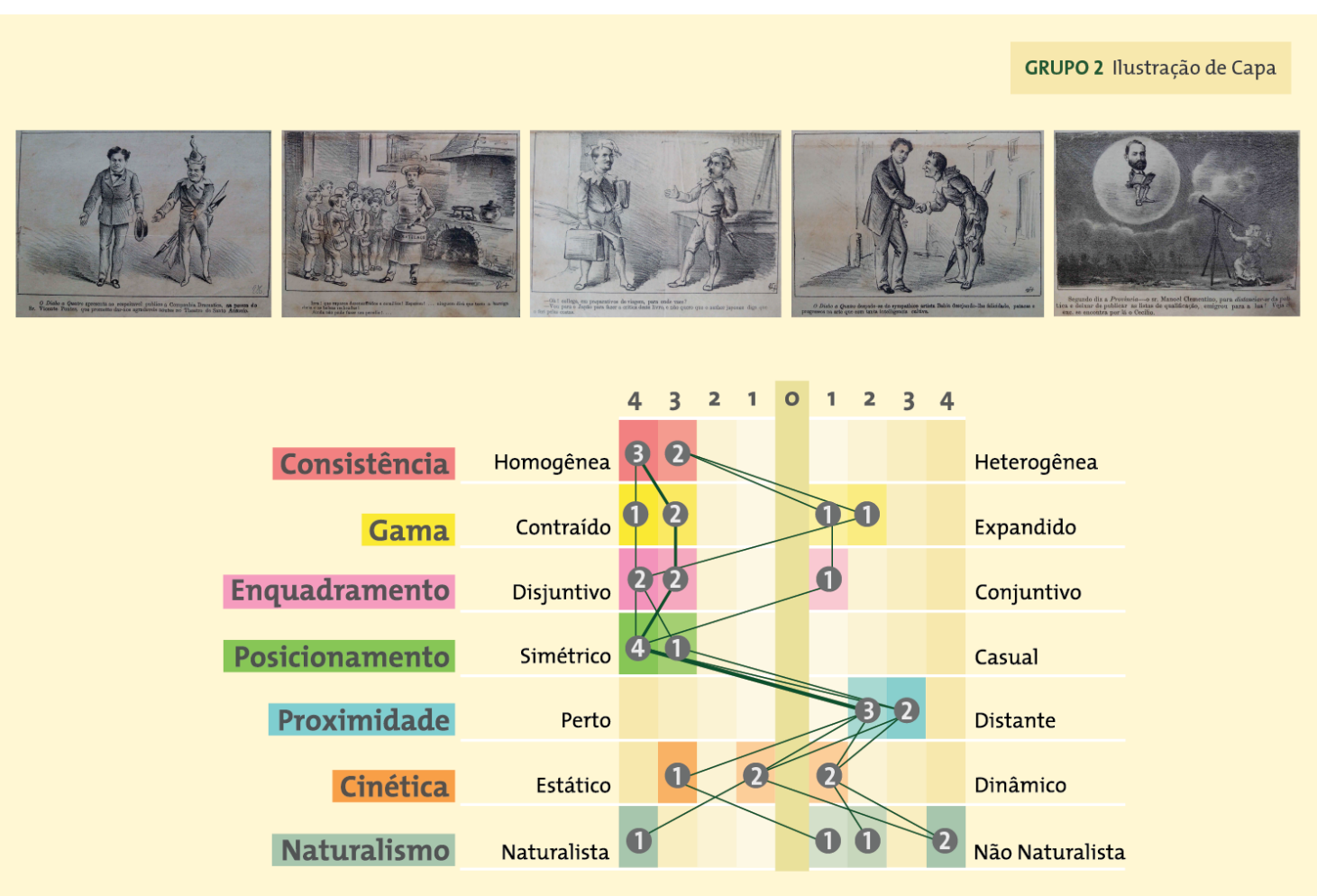

Anais do $8^{\circ}$ Congresso Internacional de Design da Informação | CIDI 2017

Proceedings of the $8^{\text {th }}$ Information Design International Conference । CIDI 2017 
As segundas tabelas (figuras 21 e 22) derivam das primeiras e os números que demarcaram a quantidade de repetições nas marcações dos níveis de cada polo deram lugar a ordem alfabética de $A$ a $E$, tendo como objetivo identificar a localização de cada ilustração na tabela.

Figura 21: Tabela 2 de resumo de resultados do Grupo 1

Fonte: Elaborada pelos autores, com base na pesquisa realizada.

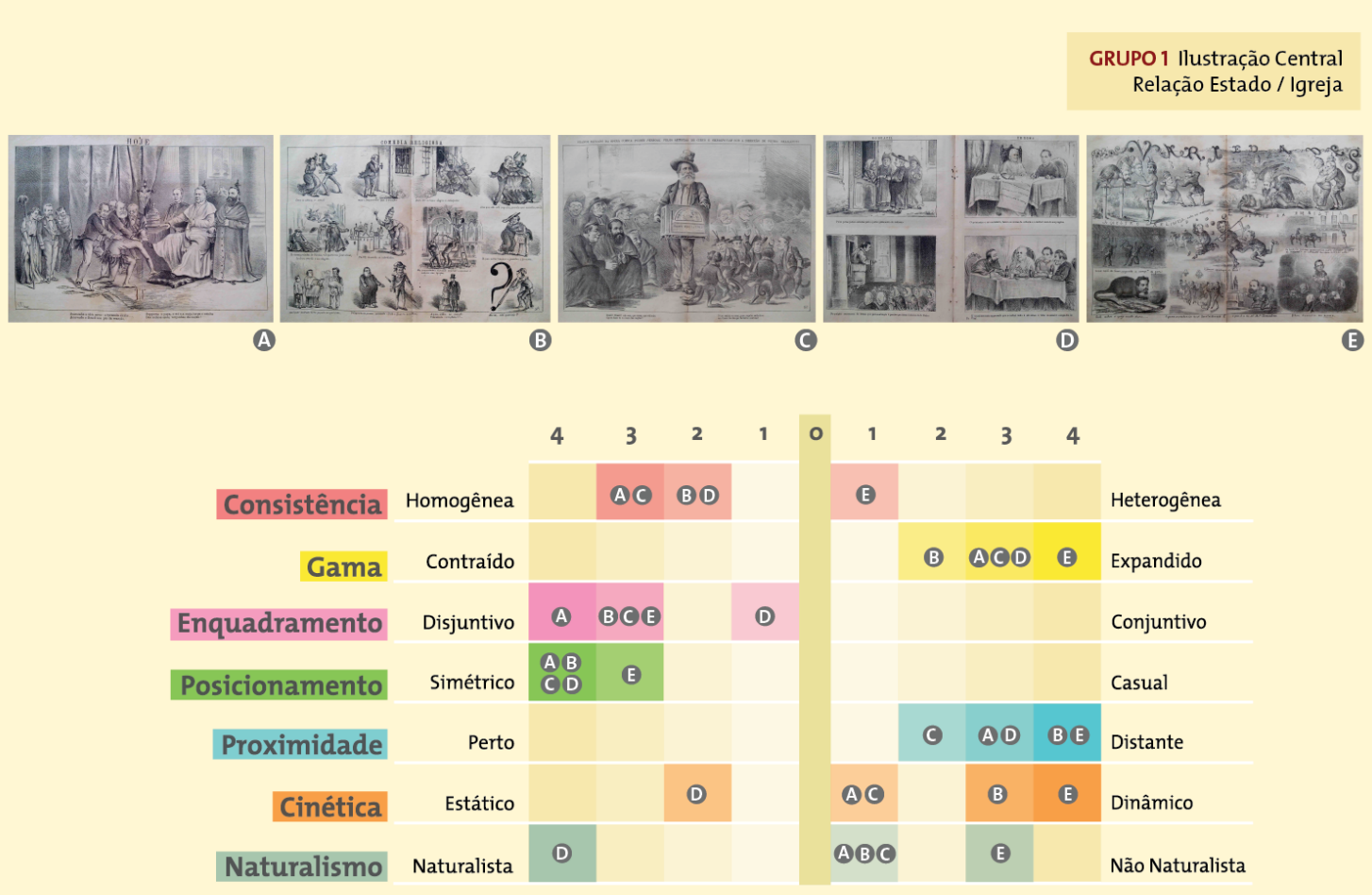

Figura 22: Tabela 2 de resumo de resultados do Grupo 2.

Fonte: Elaborada pelos autores, com base na pesquisa realizada.

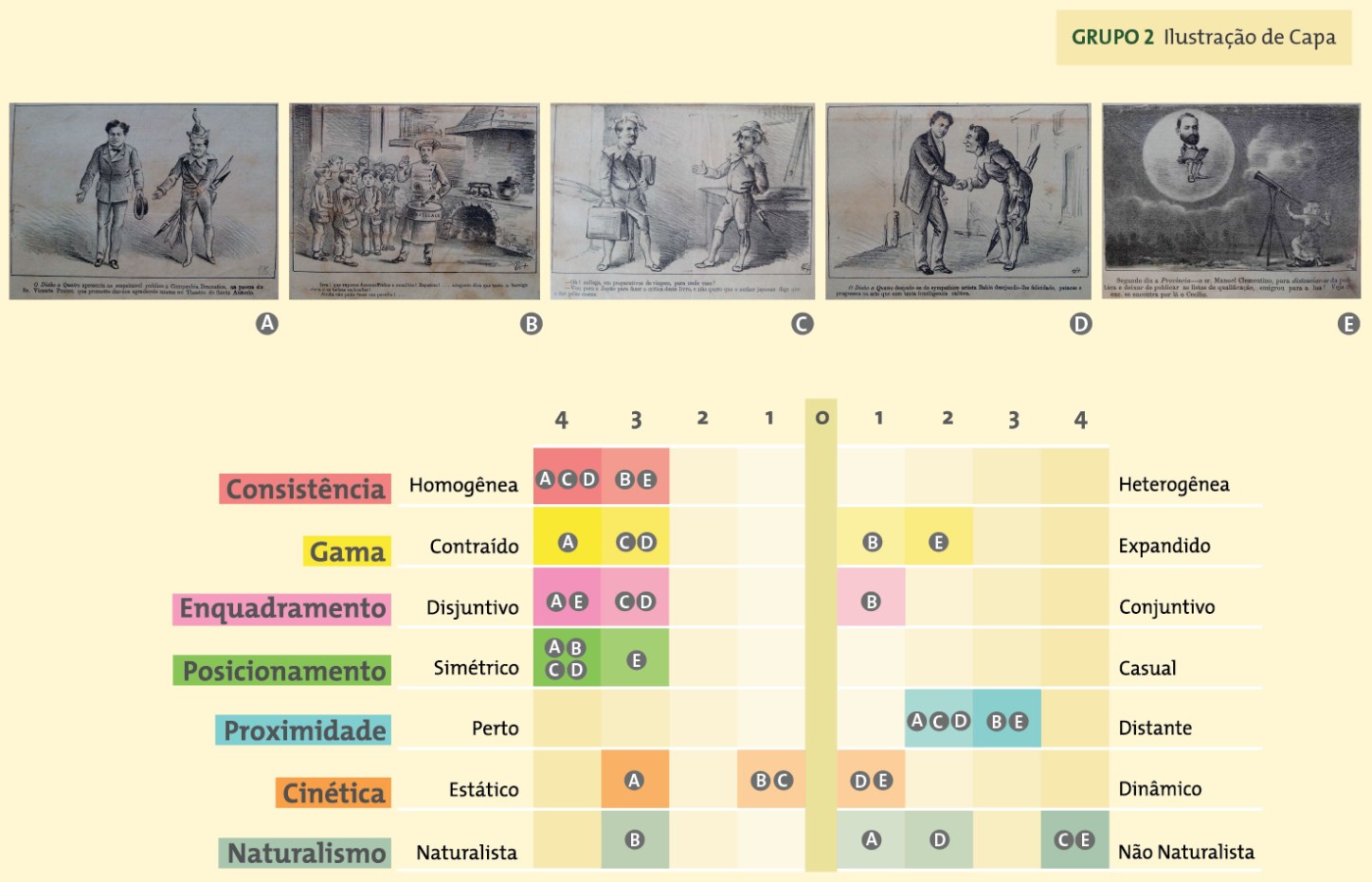

Anais do $8^{\circ}$ Congresso Internacional de Design da Informação | CIDI 2017

Proceedings of the $8^{\text {th }}$ Information Design International Conference | CIDI 2017 
Após a observação das tabelas de resumo foi possível traçar as características gerais de cada grupo que estão expressas a seguir na (figura 23), onde os polos e os níveis da escala de 1 a 4 que mais possuíram marcações estão representados. Cinco variáveis (Consistência, Enquadramento, Posicionamento, Proximidade, Naturalismo) mantiveram seus polos semelhantes apesar de apresentarem variações na escala de níveis. A diferença mais considerável foi evidenciada nos polos das variáveis Gama e Cinética que aparecem em destaque na tabela.

Figura 23: Tabela de características gerais dos Grupos 1 e 2

Fonte: Elaborada pelos autores, com base na pesquisa realizada.

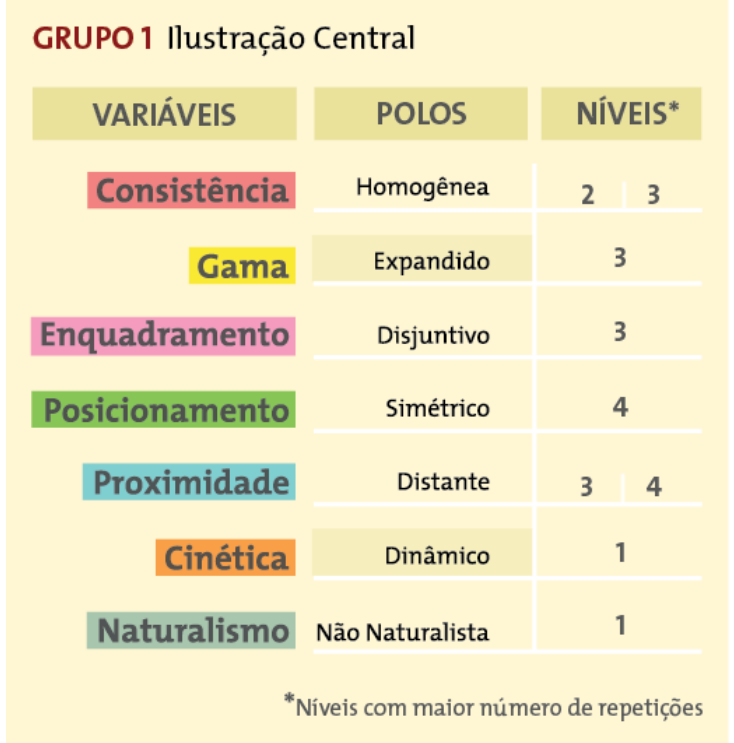

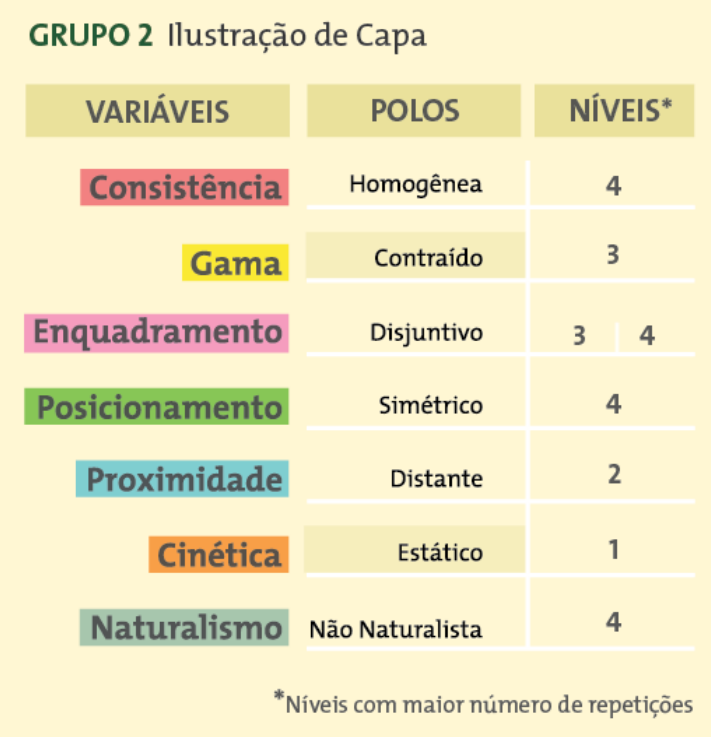

Foi possível concluir a partir deste estudo que ambos os grupos apresentam características semelhantes como: a homogeneidade na técnica de elaboração das ilustrações através da litografia; os elementos, personagens e ações representadas geralmente ocorrem no espaço do quadro ou suporte; de maneira a transmitir uma ordem ou simetria; e que praticamente todas as ilustrações possuem algum elemento ou ação que não existe no mundo real.

As maiores diferenças entre os grupos foram evidenciadas nos seguintes aspectos: as ilustrações centrais (grupo 1) apresentaram riqueza de detalhes, maior quantidade de traços, elementos de cenário e sombreamento que transmite a noção mais detalhada de profundidade do que as ilustrações de capa (grupo 2) que se apresentaram mais simples e com menos riqueza de detalhes; apesar de ambos os grupos apresentarem a variável Proximidade no polo Distante ao compararmos os níveis marcados em cada grupo, fica claro que as ilustrações centrais (grupo1) possuem uma distância maior dos elementos e ações do desenho em relação aos olhos do observador; a sensação de movimento nos personagens e ações também foi maior nas ilustrações centrais (grupo 1) enquanto que nas ilustrações de capa (grupo 2 ) os movimentos são quase estáticos.

\section{Considerações Finais}

Nos estudos iniciais deste artigo foi realizado um levantamento a respeito do estado da arte das metodologias que ligavam o design da informação a artefatos de memória gráfica. Entretanto no decorrer da pesquisa foi possível evidenciar que as etapas do processo metodológico encontradas nos artigos selecionados já estavam sendo utilizadas pelos autores deste estudo em seu processo de pesquisa. Assim decidimos utilizar o próprio objeto de pesquisa, o trabalho de um artista gráfico do final do século XIX denominado Antonio Vera Cruz, para exemplificar as etapas do processo metodológico encontradas nos artigos, dando 
destaque para um experimento realizado a partir do modelo analítico proposto por Clive Ashwin em 1979, citado em alguns dos artigos analisados.

Após o experimento foi possível constatar que o estudo e a aplicação do modelo analítico de Clive Ashwin, mesmo que neste pequeno espaço amostral de dez ilustrações pôde demonstrar características do estilo gráfico de Vera Cruz. Evidenciando que existem semelhanças nos polos de cinco varáveis (Consistência, Enquadramento, Posicionamento, Proximidade, Naturalismo) dos grupos analisados. As particularidades nos polos das variáveis Gama e Cinética talvez possuam ligação com o espaço destinado a estas ilustrações no periódico, visto que as ilustrações centrais ocupam duas páginas, enquanto que as ilustrações de capa ocupam um quadro na metade de uma página. Com mais espaço para trabalhar o desenho Vera Cruz pôde desenvolver ilustrações centrais ricas em detalhes e com maior quantidade de traços (Gama - Expandido) e consequentemente apresentando mais elementos (personagens e cenários) nas ilustrações centrais conseguiu transmitir uma maior sensação de movimento nas ações que ocorrem nas mesmas (Cinética - Dinâmico).

Como o foco deste artigo foi verificar se o modelo proposto por Ashwin funcionaria em nosso objeto de estudo, neste primeiro momento características contextuais, tradições ou marcas culturais que também são importantes na definição de um estilo gráfico e que podem ser encontradas em outros modelos analíticos ainda não foram destacadas. Entretanto ressaltamos que em estudos futuros este modelo de Ashwin complementado a outros pode ser extremamente enriquecedor tanto para os avanços do processo de pesquisa, resgate $\mathrm{e}$ preservação do trabalho de Antonio Vera Cruz, como para estudos semelhantes a este. Porquanto compreendendo, numa concepção ampliada, que o design contemporâneo é também uma espécie de continuidade do que já foi feito no passado.

\section{Referências}

ASHWIN, C. 1979. The ingredients of style in contemporary illustration: A case study. Information Design Journal, Amsterdam, v. 1, n. 1, p. 51-67.

CAVALCANTI, L. de H. 1996. Humor Diário: a ilustração humorística do Diário de Pernambuco (1914-1996). Recife: Editora Universitária da UFPE.

2005. Historia del Humor Grafico en el Brasil. Espanha: Editorial Milênio Fundação Universidad de Alcalá.

CUNHA LIMA, E. L. 2000. F. H. Carls, M. Dreschler, L. Krauss e C. Frese alemães a serviço da litografia comercial em Recife. In: Anais Congresso Brasileiro de Pesquisa e Desenvolvimento em Design, Novo Hamburgo, RS.

HOORNAERT, E. 1983. História da Igreja no Brasil: ensaio de interpretação a partir do povo. Petrópolis: Vozes.

JACOBSON, R. 2000. Information design. Cambridge (MA): The MIT Press.

MAGNO, L. 2012. História da caricatura brasileira: os precursores e a consolidação da caricatura no Brasil. Rio de Janeiro: Gala Edições de Arte.

MEGGS, P. B. 2009. História do Design Gráfico. São Paulo: Cosac Naify.

MELO, C. H. de; RAMOS, E. 2011. Linha do Tempo do Design Gráfico no Brasil. São Paulo: Cosac Naify.

NASCIMENTO, L. do. 1970. História da imprensa de Pernambuco (1821-1954) v. 5: Periódicos do Recife 1851-1875. Recife: Editora da Universidade Federal de Pernambuco.

1972. História da imprensa de Pernambuco (1821-1954) v. 6: Periódicos do Recife 1876-1900. Recife: Editora da Universidade Federal de Pernambuco.

QUERINO, M. R. 1911. Artistas Bahianos - indicações biographicas. $2^{\circ}$ edição. (melhorada, cuidadosamente revista). Bahia: Officinas da Empresa "A Bahia". 


\section{Artigos Analisados}

ALMEIDA, S.; COUTINHO, S. G. 2012. Design da informação ao serviço da memória gráfica. In: Anais do $10^{\circ}$ Congresso Brasileiro de Pesquisa e Desenvolvimento em Design, São Luís.

ARAGÃO, I. R.; BARRETO CAMPELLO, S. 2011. Referências, recorrências e cópias nos elementos verbais da Coleção Imagens Comerciais de Pernambuco (ICP). In: Anais do $5^{\circ}$ Congresso Internacional de Design da Informação. Florianópolis.

ARAGÃO, I. R.; BARRETO CAMPELLO, S.; RAMOS, H.; SAMPAIO, M. 2008. Catalogação e Análise dos Rótulos de Aguarde do Laboratório Oficina Guaianases de Gravura. In: Anais do $8^{\circ}$ Congresso Brasileiro de Pesquisa e Desenvolvimento em Design. São Paulo.

BORBA, M. R. R .; WAECHTER, H. da N. 2014. Estudos de variáveis gráficas sem auxílio da concepção de imagens instrumentais de campanhas de saúde. In: Anais do $11^{\circ}$ Congresso Brasileiro de Pesquisa e Desenvolvimento em Design. Gramado.

BUGGY, L. A. C. 2011. A relação das figuras humanas e dos caracteres alfabéticos nas capitulares de Manoel Bandeira. In: Anais do $5^{\circ}$ Congresso Internacional de Design da Informação. Florianópolis.

CUNHA LIMA, E. L.; ARAGÃO, I. R. A.; FARIAS, P. L. 2011. Catálogos de tipos móveis: contribuições para a história (tipo) gráfica brasileira. In: Anais do $5^{\circ}$ Congresso Internacional de Design da Informação. Florianópolis.

FINIZOLA, M. F.; COUTINHO, S. G. 2010. Uma Classificação Tipográfica para os Letreiramentos Populares. In: Anais do $9^{\circ}$ Congresso Brasileiro de Pesquisa e Desenvolvimento em Design, 2010, São Paulo.

2011. Identificação de padrões na linguagem gráfica verbal, pictórica e esquemática dos letreiros. In: Anais do $5^{\circ}$ Congresso Internacional de Design da Informação. Florianópolis.

OLIVEIRA, T. C. S.; ARAÚJO, K. 2011. Da litografia ao off-set: uma reflexão sobre os processos de racionalização técnica e gráfica em rótulos de cachaça pernambucanos. In: Anais do $5^{\circ}$ Congresso Internacional de Design da Informação. Florianópolis.

PIAIA, J. S.; PFÜTZENREUTER, E. do P. 2015. Identidade visual dos primeiros catálogos da Pinacoteca: relações históricas. In: Anais do $7^{\circ}$ Congresso Internacional de Design da Informação, São Paulo: Blucher.

REIS, S. R.; CUNHA LIMA, E. L.; CUNHA LIMA, G. C. 2015. Memória gráfica brasileira - Da memória ao cliente: o caso das capas de disco de vinil. In: Anais do $7^{\circ}$ Congresso Internacional de Design da Informação, São Paulo: Blucher.

WAECHTER, H. da N.; LINS, M.; XAVIER, P. 2011. Design, linguagem, gênero e memória Explorações teóricas e analíticas. In: Anais do $5^{\circ}$ Congresso Internacional de Design da Informação. Florianópolis.

\section{Sobre o(a/s) autor(a/es)}

Íkaro Santhiago Câmara Silva Oliveira; Mestrando, UFPE, Brasil <ikarocamara@gmail.com> Solange Galvão Coutinho, PhD, UFPE, Brasil <solangecoutinho@globo.com> 